\title{
AUXÍLIO-RECLUSÃO EM TEMPOS DE CULTURA DO MEDO
}

\author{
Tiago Adami Siqueira* \\ Marco Aurélio Serau Junior ${ }^{* *}$
}

\begin{abstract}
RESUMO
Trata-se de ensaio voltado para a análise da importância do auxílioreclusão em uma sociedade dominada pela cultura do medo. $\mathrm{O}$ artigo contextualiza a proteção previdenciária enquanto um direito fundamental, bem como a importância do auxílio-reclusão para o equilíbrio social e a manutenção econômica dos dependentes de segurados do Regime Geral de Previdência Social. O ensaio também discute a visão de parcela da sociedade a respeito desse benefício previdenciário, acentuando a intolerância social na pós modernidade.
\end{abstract}

PALAVRAS-CHAVE: Auxílio-Reclusão. Cultura do Medo. Direitos Fundamentais. Previdência Social.

\begin{abstract}
That refers to an assey turned to analyses of importance of reclusion aid in a society controlled by the culture of fear. The text describes social security protection while being a fundamental right, as well as the importance of reclusion aid to social balance and economical maintenance of dependents of social security general management. The essay also refers to connection between distorted sight that some people have of such social security benefit and the social intolerance that goes around society on post-modernity.
\end{abstract}

KEY WORDS: Reclusion Aid. Culture of Fear. Fundamental Right. Social Security.

\footnotetext{
Mestrando em Direito e Sociedade pelo Programa de Pós-Graduação da Universidade La Salle.

** Professor na UFPR, nas áreas de Direito do Trabalho e Previdenciário. Doutorado e Mestrado em D. Humanos pela USP.
} 


\section{INTRODUÇÃO}

Este ensaio analisa a importância do benefício previdenciário do auxílio-reclusão, destacando que esse exame é realizado em contexto social permeado pela cultura do medo.

O artigo contextualiza a proteção previdenciária como um direito fundamental, o que produz relevância na análise que se pretende empreender a respeito da importância social do benefício de auxílio-reclusão.

Em outro momento, também se apresenta a relevância da concessão do auxílio-reclusão para o equilíbrio social e a manutenção econômica dos dependentes de segurados do Regime Geral de Previdência Social, reais destinatários da proteção social no caso dessa contingência social.

O ensaio também discute a visão de parcela da sociedade a respeito desse benefício previdenciário, demonstrando a acentuada intolerância no cenário atual.

O método utilizado na elaboração desta pesquisa é eminentemente analítico-bibliográfico, não tendo sido realizado trabalho de campo - a despeito de não se poder desprezar a experiência profissional de ambos os coautores.

\section{A PROTEÇÃO PREVIDENCIÁRIA ENQUANTO UM DIREITO FUNDAMENTAL}

No Brasil a proteção previdenciária é classificada e considerada um direito fundamental, tanto pelo quesito ontológico, ligado à sua estrutura, finalidade e funções, como pelo quesito dogmático normativo, estando garantida na Constituição Federal e em diversos Tratados de Direito Internacional dos Direitos Humanos, inclusive no âmbito da OIT - Organização Internacional do Trabalho (SERAU JR., 2015, p. 31).

É importante frisar essa característica de direito fundamental de todo e qualquer direito previdenciário ao se efetuar a análise do impacto social do auxílio-reclusão, ele também direito humano.

É que o benefício de auxílio-reclusão é um benefício previdenciário constantemente criticado nos canais de mídia e, de modo geral, também pela população. Entretanto, as pessoas, na 
maioria dos casos, não sabem qual o real cabimento deste benefício e a quem efetivamente busca proteger. Tratado comumente como uma espécie de "bolsa-preso" pelos cidadãos comuns, na verdade o auxílio-reclusão é um benefício extremamente importante para a manutenção econômica das famílias de baixa renda, voltado especificamente ao sustento dos dependentes de segurado que venha a ser detido ou recluso.

As sociedades desiguais do ponto de vista socioeconômico tendem a ter elevados índices de criminalidade e violência. $\mathrm{O}$ auxílio-reclusão é um benefício de extrema relevância, pois alberga na sua proteção justamente os dependentes daqueles segurados que se encontram em condições de vulnerabilidade social e vêm a ser presos.

Portanto, faz-se necessário reforçar a ideia de proteção previdenciária enquanto um direito fundamental.

Não raro, tratados como sinônimos direitos humanos e direitos fundamentais, pelo menos do ponto de vista conceitual, não possuem a mesma representação. Direitos fundamentais são aqueles direitos inerentes ao ser humano, positivados na esfera constitucional do Estado, enquanto que os direitos humanos guardam relação com os documentos de direito internacional, por serem posições reconhecidas como essenciais ao ser humano enquanto tal, independente de sua vinculação ao ordenamento constitucional interno. Assim, os direitos humanos possuem uma validade universal, têm um caráter supranacional. Os direitos humanos estão ligados a própria condição de dignidade, ao passo que quando positivados no plano interno (constituições) são transformados em direitos fundamentais (SARLET, 2015, p. 29-33).

Os direitos fundamentais pretendem tutelar, sob um prisma axiológico, os interesses e necessidades básicas atinentes ao princípio da igualdade real. Sob um prisma dogmático, são aqueles direitos postos em normas de maior valor no âmbito do ordenamento jurídico, como por exemplo, na constituição e, até mesmo, advindos de tratados e convenções internacionais, sendo nestes casos denominados de direitos humanos. Porém, nem sempre existe uma ligação lógica entre estes dois prismas (SCHWARZ, 2013, p. 100).

Todavia, não se pode restringir os direitos humanos aos direitos positivados no plano internacional, se assim o fizermos, 
corremos o risco de ingressarmos em uma tautologia perversa. A essência da proteção humana, dos direitos do homem e da busca pela dignidade da pessoa humana está acima de qualquer regulamentação ou análise interpretativa formal. Tratar de direitos humanos é tratar do processo de luta pela dignidade humana, pela conquista dos direitos sociais e combate às desigualdades (HERRERA FLORES, 2009, p. 17-22).

Uma constituição ou um tratado internacional não são os criadores de direitos humanos, além do que admitir que o direito cria o direito é ir ao encontro de um positivismo retrógrado. Os direitos são materializados após lutas sociais que buscam as garantias dos bens indispensáveis para se viver com dignidade, que são: liberdade, educação, moradia, trabalho, meio ambiente, alimentação sadia, cidadania, lazer, cultura, proteção social (previdenciária), entre outros (HERRERA FLORES, 2009, p. 28-30).

As lutas sociais são geradas justamente devido às desigualdades entre os seres humanos, a busca pelo tratamento igualitário leva aos processos de construção dos direitos humanos e fundamentais. Com o direito à seguridade social e à proteção previdenciária não foi diferente, estes foram conquistados após lutas e organização social. São constantemente ameaçados e influenciados por práticas e ideias econômicas neoliberais, assim faz-se necessário, para a própria manutenção e ampliação da cobertura previdenciária, o estudo histórico da construção dos direitos humanos e seu impacto na consolidação de um direito previdenciário inclusivo.

Desta feita, os direitos humanos são o resultado provisório de lutas sociais pela dignidade humana, cujo resultado deverá ser garantido por normas jurídicas, políticas públicas e econômicas (HERRERA FLORES, 2009, p. 31-34).

Para WOLKMER (2017, p. 34): "Dessa forma, tem-se a dignidade humana enquanto conquista de uma práxis histórica de libertação como polo fundante de todas outras formas de Direito."

No mundo atual, praticamente não há Estado que não tenha aderido, ao menos em parte, aos pactos internacionais de direitos humanos. Porém, mesmo que inegável o progresso na esfera da positivação destes direitos, longe estamos de solucionar os problemas inerentes a esta matéria, principalmente pelo enorme desequilíbrio entre ricos e pobres (SARLET, 2015, p. 21-24). 
No século XIX, com a expansão da revolução industrial e o aumento das desigualdades sociais e econômicas, correntes socialistas, capitaneadas por Marx, começaram a reivindicar um comportamento mais ativo do Estado em busca de justiça social (SARLET, 2015, p. 47).

Posteriormente, com a Revolução Francesa, a liberdade individual foi afirmada frente ao poder estatal, sendo garantida a propriedade. Com isso a burguesia revolucionária pode acabar com os privilégios que eram concedidos à nobreza feudal no Estado Absolutista. Nesta época os trabalhadores foram desvinculados dos feudos e puderam vender sua mão de obra livremente. Ocorre que não demorou para alguns membros dessa emergente burguesia começarem a explorar estes trabalhadores "livres" que não detinham os meios de produção, assumindo, os burgueses, uma posição de superioridade em relação ao demais trabalhador.es Assim o Estado passou a ter que deixar sua posição passiva e iniciar sua atuação na regulação destas relações e na concessão de prestações e garantias sociais, começando a ter um papel ativo nesta seara (GALVÃO, 1981, p. 11).

Fica claro aqui o constante e evolutivo processo de lutas sociais pela conquista de direitos. Após a Revolução Francesa e com o advento da Revolução Industrial, um determinado grupo de cidadãos que não detinha propriedades e os meios de produção, passou a ser explorado, sentindo então a necessidade de uma real garantia de direitos individuais, de liberdade e igualdade.

Assim, nasce a concepção do Estado do bem-estar social (Welfare State), no qual as desigualdades são minimizadas e todos os cidadãos podem gozar dos direitos de liberdade e igualdade que foram conquistados no século anterior. Porém, na prática, apenas parte da sociedade que detinha os meios de produção, a propriedade de terras e os comércios pode usufruir destas liberdades e garantias conquistadas na Revolução Francesa.

A base do Estado do bem-estar social não é calcada somente em valores éticos, mas também como um mecanismo de controle social contra as ideias socialistas e comunistas que se difundiam no século XIX e em outros períodos da história. A proteção previdenciária é um anseio social que surge no início do século XX, sendo enquadrada pela doutrina como direitos humanos de segunda 
geração, caracterizados também pela garantia de direitos econômicos, sociais e culturais.

Os direitos trabalhistas e demais direitos sociais, inclusive os previdenciários, foram conquistados devido ao tensionamento causado pelos movimentos de lutas sociais que pleiteavam uma mudança dos sistemas político e jurídico (FREITAS JR, 2011, p. 161).

Os processos de lutas somados a inquietação popular fizeram com que a classe dominante não visse outra forma de controle social, senão, concedendo certos direitos sociais. Conforme leciona Antônio Carlos Wolkmer:

Mais especificamente sobre a peculiaridade deste processo, devemse considerar as profundas modificações sociais e econômicas ocorridas na Europa e no Ocidente: em parte, devido à amplitude dos conflitos sociais e ao consequente alargamento da "questão social"; ao crescimento de reivindicações das massas urbanas trabalhadoras, associadas, em determinado momento, às representações socialistas e anarco sindicalistas; à contribuição da Igreja Católica na afirmação de uma doutrina de justiça social; e, de outra parte, aos novos rumos do desenvolvimento do capitalismo industrial e financeiro; aos efeitos da Grande Guerra e ao decisivo impacto ideológico da Revolução Russa de 1917 (WOLKMER, 1998, p. 17-18).

A Constituição Mexicana (1917) foi a primeira a ter o status de constituição social, normatizou em seu texto, com um título específico no artigo 123, os direitos ao "Trabalho e à Previdência Social". Depois, a Constituição de Weimar (1919), na Alemanha, garantiu direitos e deveres fundamentais. Esta base constitucional influenciou várias constituições do pós-guerra, inclusive a Constituição Brasileira de 1934. A Constituição alemã foi proclamada quando o país vivia uma crise institucional, econômica e social, na qual a massa operária estava em greve e sob influência de forças socialistas. Caracterizou uma primeira tentativa de construção de uma social-democracia, unificando tanto as ideias liberais burguesas individualistas com os ideais socialistas (SANTIN, 2017, p. 126-127).

Neste diapasão, a proteção previdenciária e a organização da seguridade social como um todo são fundamentais para a diminuição das diferenças entre as camadas sociais. 
O benefício de auxílio-reclusão possui papel fundamental na proteção da camada social mais pobre e vulnerável, dotado da característica de direito fundamental, tal qual qualquer direito previdenciário, conforme os argumentos e percurso histórico narrado acima.

\section{O AUXÍLIO-RECLUSÃO E A SUA FUNÇÃO SOCIAL}

Os benefícios do Regime Geral de Previdência Social possuem um objetivo claro que é a proteção social. Têm a função de proteger os segurados e os dependentes da Previdência Social em situações de vulnerabilidade e risco social, tais como: doença incapacitante ao trabalho, invalidez, morte, maternidade e velhice. Dentre os benefícios previdenciários que protegem as situações relatadas, temos: auxílio-doença, aposentadoria por invalidez, pensão por morte, salário-maternidade, aposentadorias por idade e por tempo de contribuição.

O Estado do Bem-Estar pretende a garantia de padrões mínimos de vida digna para o indivíduo e a comunidade, considerando como necessidades básicas a expansão do emprego, a saúde e a educação. Não há dúvida de que a prisão do(a) provedor(a) da família implica consequências de ordem material, econômica e financeira àqueles que deles dependam, chegando, muitas vezes, a situações nas quais os dependentes do segurado da Previdência Social preso fiquem expostos à situação de abandono total. No modelo do Estado do Bem-Estar, não só o Estado, mas todos os indivíduos devem se empenhar pelo bem comum, isto é, devem procurar minimizar, ao menos financeiramente, as dificuldades encontradas pelos dependentes do segurado preso que perde a situação do emprego (PACHECO, 2009).

Com base na função protetiva dos benefícios do regime geral de previdência social, muitas pessoas e até canais de mídia, costumam divulgar o auxílio-reclusão como um benefício ao preso, uma espécie de "bolsa preso"".

\footnotetext{
${ }^{1}$ Um exemplo de notícia vinculada na mídia que propaga uma ideia errada do auxílio-reclusão. Disponível em: <http://www.progresso.com.br/editorial/bolsa-parapresidiarios> Acesso em: $13 \mathrm{dez} .2017$.
} 
Fazem, costumeiramente, comparações que um preso receberia um salário maior no auxílio-reclusão que um trabalhador na aposentadoria, após contribuir durante toda sua vida laboral. Ocorre que a visão protetiva e o objetivo da proteção social do auxílio-reclusão não é de amparar o preso, pelo contrário, o objetivo é amparar a família do recluso, os seus dependentes legais.

Conforme dispõe o artigo 16 da Lei 8.213/91:

“... são beneficiários do Regime Geral de Previdência Social, na condição de dependentes do segurado:

I - o cônjuge, a companheira, o companheiro e o filho não emancipado, de qualquer condição, menor de 21 (vinte e um) anos ou inválido ou que tenha deficiência intelectual ou mental ou deficiência grave;

II - os pais;

III - o irmão não emancipado, de qualquer condição, menor de 21 (vinte e um) anos ou inválido ou que tenha deficiência intelectual ou mental ou deficiência grave."

\section{Ademais:}

O legislador constituinte originário houve por bem apontar a prisão do segurado como risco social a ser coberto pelo regime previdenciário. Note-se que a prisão decorre de ato do próprio segurado, o que pode levar a críticas, mas a verdade é que o benefício é dirigido aos dependentes do segurado, como já foi dito, e não a este. Assim, a prisão do segurado de baixa renda provoca uma necessidade social, exatamente a falta de condições de subsistência dos dependentes por incapacidade laboral do recluso, o que será coberto por este benefício previdenciário (VIANNA, 2013, p. 555).

O benefício de auxílio-reclusão é um benefício previdenciário, portanto, de natureza contributiva. Muito embora, conforme já relatado, seja taxado pela opinião pública como um benefício de cunho assistencial.

A intenção do legislador foi conceder, ou seja, albergar no guarda-chuva dos benefícios previdenciários proteção à família do preso. Para tanto, o segurado (preso) necessita estar vinculado 
formalmente à previdência social, possuindo qualidade de segurado ${ }^{2}$. Portanto, fica clara a intenção do legislador em proteger apenas os dependentes do segurado recluso.

A Constituição Federal, em seu artigo 201, disciplina que será concedido auxílio-reclusão para os dependentes dos segurados de baixa renda. Destarte, além do requisito do preso estar vinculado ao Regime Geral de Previdência Social no momento de sua prisão, é necessário que o mesmo seja de baixa renda. Ou seja, a proteção previdenciária aos dependentes dos presos, por força constitucional, restringiu-se aos segurados hipossuficientes economicamente ${ }^{3}$.

O critério adotado pelo Regime Geral de Previdência Social para auferir a condição de baixa renda do segurado recluso foi o objetivo, regulamentado no artigo 116 do Decreto 3.048/99. Foi fixada uma renda limite, no momento da reclusão, para os dependentes do segurado preso terem direito ao benefício. Esta renda limite é atualizada através de portaria ministerial anualmente, respeitando os critérios de correção do salário-mínimo nacional.

Atualmente, no momento da reclusão ou no último mês contribuído, a renda mensal do segurado preso não pode ser superior a $\mathrm{R} \$ 1.319,18^{4}$.

A jurisprudência, em alguns julgados, entende que se o segurado é desempregado no momento da prisão e, portanto, não possui renda, bastaria ter qualidade de segurado para seus dependentes terem direito ao gozo do benefício ${ }^{5}$. Segundo o

${ }^{2}$ Assim dispõe o artigo 80 da Lei $8.213 / 91$ : “O auxílio-reclusão será devido, nas
mesmas condições da pensão por morte, aos dependentes do segurado recolhido à
prisão, que não receber remuneração da empresa nem estiver em gozo de auxílio-
doença, de aposentadoria ou de abono de permanência em serviço."
${ }^{3} \mathrm{Na}$ vigência da Lei $8.213 / 91$, após a Emenda Constitucional $\mathrm{n}^{\circ}$ 20, são requisitos
para a concessão do auxílio-reclusão: a) efetivo recolhimento à prisão; b)
demonstração da qualidade de segurado do preso; c) condição de dependente de
quem objetiva o benefício; d) prova de que o segurado não está recebendo
remuneração de empresa ou de que está em gozo de auxílio-doença, de
aposentadoria ou abono de permanência em serviço; e) renda mensal do segurado
inferior ao limite legal estipulado.
${ }^{4}$ Valor fixado por portaria do Ministério da Fazenda ${ }^{\circ} 15$, de 16 de janeiro de 2018
(Publicada no D.O.U de $17 / 01 / 2018$, seção 1 , página 28 ).
${ }^{5}$ Conforme observa-se nas decisões do Tribunal Regional da $4{ }^{a}$ Região, proferidas
nos seguintes processos: a) TRF4, AC 5037172-63.2015.4.04.7000, SEXTA
TURMA, Relator JOÃO BATISTA PINTO SILVEIRA, juntado aos autos em 
entendimento jurisprudencial dominante, nos casos de desemprego do segurado recluso a condição de vulnerabilidade social é presumida,

$O$ requisito renda também causa outras divergências entre o entendimento da autarquia previdenciária (INSS) e a jurisprudência, pois, diante da expressão "auxílio-reclusão para os dependentes dos segurados de baixa renda", prevista no inciso IV do artigo $201 \mathrm{da} C F$, há duas possíveis interpretações.

Alguns sustentam que este requisito refere-se ao segurado, ou seja, exige-se que antes de ser preso, o segurado não estivesse recebendo salário maior que o estipulado em portaria ministerial. Portanto, o segurado (preso) é quem deveria ser de baixa renda. Por sua vez, outra corrente sustenta que o requisito de baixa renda deveria ser analisado em relação aos dependentes, uma vez que o benefício seria a eles destinado. Portanto, para estes, o dependente é quem deveria ser hipossuficiente economicamente.

Neste sentido foi o enunciado da Súmula 5 da Turma Regional de Uniformização dos Juizados Especiais do Tribunal Regional Federal da $4^{\mathrm{a}}$ Região: "para fins de concessão do auxílio-reclusão, o conceito de renda bruta mensal se refere à renda auferida pelos dependentes e não à do segurado recluso" ${ }^{\prime 6}$.

Porém, nos julgamentos dos Recursos Extraordinários $\mathrm{n}^{\circ}$ 587.365 e 486.413, o Supremo Tribunal Federal pacificou a discussão, consolidando o entendimento de que o requisito de baixa renda está ligado ao segurado, e não aos seus dependentes. Aplicouse, portanto, a interpretação literal e teleológica do dispositivo constitucional.

A proteção concedida aos familiares do segurado recluso assemelha-se a da pensão por morte, pois em ambos os casos o segurado instituidor passa a não poder mais prover seu lar, seja por estar detido, ou no caso da pensão por morte, em decorrência de óbito. Por óbvio, o auxílio-reclusão será mantido somente até a soltura do preso.

13/12/2017 e b) TRF4 5036626-61.2017.4.04.9999, SEXTA TURMA, Relator JOÃO BATISTA PINTO SILVEIRA, juntado aos autos em 13/12/2017.

${ }^{6}$ A súmula foi editada em 2008, mas cancelada na sessão de 04-12-2009, Proc. $\mathrm{n}^{\circ}$ 2008.71.95.001809-3. 
O auxílio-reclusão também será concedido aos presos em prisão preventiva ou temporária, regime fechado ou semiaberto, sendo vedada ao preso exercer atividade remunerada. Não cabe a concessão de auxílio-reclusão aos dependentes do segurado que esteja em livramento condicional ou que cumpra pena em regime aberto, justamente pelo fato de poderem exercer atividade remunerada, e assim proverem economicamente seus dependentes.

Sendo um direito fundamental, considera-se que a proteção do auxílio-reclusão não deveria ser restritiva ao quesito baixa renda, e que esta restrição viola princípios basilares da própria Carta Magna, como: isonomia e a dignidade da pessoa humana.

Partindo da ideia central de que a proteção do auxílio-reclusão funciona como salvaguarda para as famílias que perdem seus provedores por algum período de tempo, torna-se contraditório, do ponto de vista axiológico, conceder esta proteção apenas àquelas famílias que são de baixa renda.

Um elemento que reforça esta visão é o fato do auxílioreclusão estar previsto no artigo 229 da Lei 8.112/91, lei que instituiu o Regime Jurídico dos Servidores Públicos Civis da União, das autarquias, inclusive as em regime especial, e das fundações públicas federais, sem a necessidade do segurado (servidor) recluso precisar comprovar ser de baixa renda, e não fixando limite de ganhos mensais para os dependentes terem direito ao benefício.

Entende-se, portanto, que o auxílio-reclusão deveria ser concedido levando-se em conta apenas dois requisitos: a) qualidade de segurado; b) a existência de dependente válido. Porém, não foi esta a opção do legislador que vinculou o gozo do benefício à condição de baixa renda do segurado recluso.

\section{A CULTURA DO MEDO E A LEGITIMAÇÃO DO AUTORITARISMO COMO FORMA DE SUPRESSÃO DE GARANTIAS SOCIAIS}

A sociedade brasileira contemporânea está imersa em um sentimento de medo relacionado à insegurança. Há uma percepção geral que após a consolidação do estado democrático ocorreu um aumento da criminalidade no país. Muitas vezes, esta percepção legitima condutas autoritárias que contrariam as garantias 
conquistadas na Constituição Federal de 1988. Pastana define que:

Cultura do medo representa a somatória dos valores, comportamentos e do senso comum que, associados à questão da criminalidade, reproduz a ideia hegemônica de insegurança e, com isso, perpétua uma forma de dominação marcada pelo autoritarismo e pela rejeição aos princípios democráticos. Quando afirmamos a existência de uma cultura do medo na atualidade, por exemplo, não estamos dizendo que o medo é exclusivo deste momento. Na verdade o medo sempre acompanhou o homem, haja vista a busca permanente de unidade, coesão e a organização em grupo para se fortalecer e se proteger, ou seja, para enfrentar e eliminar as causas do medo (PASTANA, 2005, p. 183).

Atualmente, vive-se uma espécie de sentimento coletivo de insegurança que acaba alterando o modo de vida das pessoas. Porém, esta percepção nem sempre está ligada a um real aumento da violência criminal. Neste sentido, Pastana complementa:

Atualmente o problema social da violência urbana torna-se secundário diante de um problema ainda mais pungente que é o medo generalizado e exacerbado do crime. $\mathrm{O}$ medo associado à criminalidade nas metrópoles como São Paulo tornou-se um problema que se incorporou ao modus vivendi da população urbana. É hoje um assunto valorizado pela imprensa e pelas autoridades, determinando mudanças no comportamento e hábitos sociais. Cada vez mais, as cidades assumem feições ditadas por uma arquitetura do medo. Muros mais e mais altos, cercas em volta das residências, sofisticados sistemas de segurança e alarme. assim como se verificam outros fenômenos correlatos: crescimento visível das empresas privadas de vigilância, elevada quantidade de armas de fogo em circulação, êxodo de zonas e regiões onde o risco de se transitar sozinho pressupõe-se b elevado, além de demais mecanismos de autoproteção. Diante disso, os indivíduos e as instituições moldam seus comportamentos à nova realidade $\mathrm{e}$ reorientam-se para conviver com o medo e a insegurança, sob a tensão e a expectativa de serem vítimas de ofensas criminais (PASTANA, 2005, p. 184).

Constata-se que um grupo crescente de pessoas não está preocupado em manter as garantias advindas com o estado 
democrático de Direito, pelo contrário, estas pessoas mantêm um discurso que legitima a punição a qualquer custo, sem a observância de princípios basilares como: a presunção de inocência, dignidade da pessoa humana e o devido processo legal. A sociedade atual, cada vez mais, endossa condutas autoritárias de agentes públicos de segurança.

Agentes políticos que em seus discursos "pregam" a utilização de práticas violentas contra supostos "bandidos"; que são contra as garantias constitucionais de liberdade, presunção de inocência, dignidade da pessoa humana são tidos como "mitos", heróis, salvadores.

Políticas de desencarceramento em outros países apresentam excelentes resultados, porém, no Brasil, há uma espécie de consenso popular que a melhor forma de diminuir os índices da violência urbana é a prisão. Este pensamento finalístico não leva em consideração todo um cenário complexo de grande desigualdade, falta de oportunidades de ascensão social, educação e saúde pública de baixa qualidade.

A cultura do medo acaba segregando as pessoas, fazendo com que a sociedade fique homogênea e dificultando a convivência entre cidadãos diferentes (culturalmente, economicamente). As pessoas acabam por conviver apenas em seus ciclos sociais, morando em condomínios fechados, cercando-se de muros, comprando apenas em lugares com segurança particular (shoppings e centros comerciais privados). Segundo Pastana, este comportamento só faz aumentar as desigualdades sociais e a própria sensação de insegurança:

Seja como for, esses enclaves representam um espaço que contradiz diretamente os ideais de heterogeneidade, acessibilidade e igualdade que ajudaram a organizar tanto o espaço público moderno quanto as modernas democracias. Privatização, cercamentos, policiamento de fronteiras e técnicas de distanciamento criam um outro tipo de espaço público: fragmentado, articulado em termos de separações rígidas e segurança sofisticada, e no qual a desigualdade é um valor estruturante. No novo tipo de espaço público, as diferenças não devem ser postas de lado, tomadas como irrelevantes, negligenciadas. Nem devem também ser disfarçadas para sustentar ideologias de igualdade universal ou de pluralismo cultural. $\mathrm{O}$ novo meio urbano reforça e valoriza a desigualdade e a separação e é, portanto, um espaço público não democrático (PASTANA, 2005, p. 188). 
Bauman sintetizou bem os efeitos da cultura do medo sobre a segregação social, balizada em fatores econômicos, e os efeitos desta sobre a aumento exponencial das desigualdades:

Em síntese, a transformação nasce dos efeitos produzidos por um duplo movimento: por um lado, é nas grandes áreas urbanas que se concentram as funções mais avançadas do capitalismo, que tem se reacomodado segundo uma lógica de rede, cujos núcleos estruturais são justamente os centros globais. Por outro, as cidades tornam-se objeto de novos e intensos fluxos de população e de uma profunda redistribuição da renda: seja nos bairros nobres, com a formação de uma elite global móvel e altamente profissionalizada, seja nos bairros populares, com a ampliação dos cinturões periféricos, onde se junta uma enorme quantidade de populações deserdadas. Em suma, a cidade social democrata que se afirmou no segundo pósguerra torna-se ameaçada em suas fundações, pois o tecido social é submetido a intensas pressões que produzem uma verticalização crescente: os ricos tendem a se tornar ainda mais ricos, desfrutando as oportunidades disponibilizadas pela ampliação dos mercados, enquanto os mais pobres afundam na miséria, destituídos de sistemas de proteção social (BAUMAN, 2005, p. 12).

Outra questão central é o próprio sistema prisional brasileiro que não cumpre sua função de ressocializar o apenado. Segundo dados do Ministério da Justiça ${ }^{7}$, o Brasil ocupa hoje a posição de quarto país com a maior população carcerária do mundo, com mais de 600.000 presos abarrotados em 370.000 vagas. Isso além de representar uma violação aos direitos fundamentais, demonstra a total ineficiência do sistema carcerário brasileiro.

O preso no Brasil sofre muita discriminação, fica estigmatizado quase que de forma perpétua.

Essa discriminação acaba por se estender aos seus familiares. Assim, a proteção previdenciária se torna fundamental, de sorte que o Brasil inova em proteger através do Regime Geral de Previdência Social os dependentes dos segurados presos de baixa renda.

Tal proteção previdenciária é um grande avanço social em busca

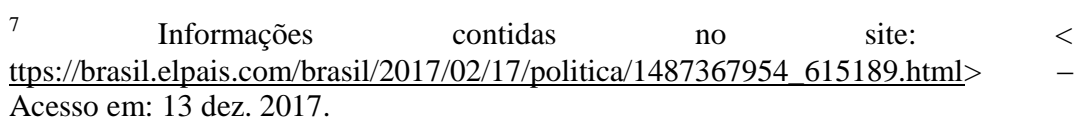


da efetivação de uma real ressocialização do apenado e da diminuição que o impacto de uma reclusão pode trazer a todo grupo familiar. Não se pretende aqui fomentar que réus condenados, com trânsito em julgado, em suas ações penais fiquem impunes, mas sim que o sistema de punição funcione como um meio de ressocialização eficaz.

A pena, ainda que do ponto de vista sentimental e psicológico também acabe sendo cumprida pelos familiares do apenado (extrapolando o mandamento constitucional que indica que a pena não passará da pessoa do preso), não pode influenciar na situação socioeconômica destes.

Vislumbra-se, desta forma, a importância do auxílio-reclusão como um benefício que tem a função de manutenção econômica dos familiares do segurado preso, não se constituindo em qualquer sorte de "favor" ao detento ou "bolsa preso".

A imprensa, assim como distorce em muitas situações, a real proteção e importância do auxílio-reclusão, ainda propaga o sentimento de insegurança na sociedade.

Ressalta-se que a imprensa tem parcela significativa de responsabilidade nesta estigmatização. No caso específico da violência criminal o processo de produção da informação, por um lado, não reflete a realidade e a intensidade dos eventos que deveria recobrir; por outro, adequa-se à concepção dominante de violência e de sujeitos violentos que a sociedade hegemonicamente retém em seu imaginário (PASTANA, 2005, p. 189).

Percebe-se que em uma sociedade fragmentada e desigual, o preso e seus familiares acabam sendo marginalizados e o mesmo se reflete na opinião social quanto à pertinência do auxílio-reclusão enquanto proteção previdenciária. Opta-se por propagar notícias inverídicas e excluir ainda mais o preso e seus familiares do convício social, como uma espécie de fuga da realidade.

Neste raciocínio crítico também se deve levar em consideração aquilo que WACQUANT (2007) tem compreendido como um movimento de substituição do Estado Social pelo Estado Penal: o Estado abandona suas políticas sociais, inclusive previdenciárias, e passa a realizar a gestão da sociedade através de políticas penais, inclusive de encarceramento em massa. 
Segundo GRAHAM (2016, p. 52-53):

“O predomínio de modelos neoliberais de administração nas últimas três décadas, combinando com a difusão de modelões punitivos e autoritários de policiamento e controle social, exacerbou as desigualdades urbanas. Como resultado, os pobres da cidade são muitas vezes confrontados com redução nos serviços públicos, de um lado, e uma palpável demonização e criminalização, do outro".

\section{CONCLUSÕES}

A estruturas sociais, em parte, são garantidas pela manutenção da paz social (GNATA, 2014, p. 84). Para a manutenção desta ordem social e, consequentemente, a diminuição das desigualdades geradas pelo capitalismo, é necessário que se ofereça assistência aos membros hipossuficientes da sociedade (GIDDENS, 2005, p. 272).

Os mecanismos de proteção social que o Estado oferece são fundamentais para a manutenção da estabilidade social, pois estes funcionam, ou ao menos deveriam funcionar, como ferramentas para diminuição das desigualdades. A Previdência Social é um desses pilares, sendo fundamental para a proteção dos trabalhadores em momentos de vulnerabilidade social. Dentre estas destaca-se a reclusão, situação na qual o trabalhador fica impedido de prover o sustento de sua família devido a sua condição de preso.

Roosevelt ${ }^{8}$, na concepção do Welfare State, propôs uma segunda carta de Direitos que incorporou garantias sociais e estabeleceu uma nova base de segurança nos Estados Unidos e, depois, serviu como modelo para outros países. Para ele, a verdadeira liberdade individual não existe sem segurança econômica e independência financeira mínima: "homens com necessidades não são livres." Ele acreditava que pessoas com fome e desempregadas eram a matéria-prima para as ditaduras (CARBOBELL, 2010, p. 52).

\footnotetext{
${ }^{8}$ Franklin Delano Roosevelt, então presidente dos Estados Unidos, em um famoso discurso no dia 11 de janeiro de 1944 no qual propôs diversas ações para implemento de políticas e programas sociais. A ampliação da intervenção do Estado, com o planejamento econômico, ficou conhecida como "New Deal". Foi uma resposta a crise econômica de 1929 que colocou em xeque a viabilidade das medidas econômicas liberais, que apontava o mercado capitalista como o instrumento ideal para se alcançar o equilíbrio econômico e social, sem a intervenção maciça do Estado.
} 
Nesta análise, pode-se auferir, inclusive, que o auxílio-reclusão contribui para a redução da criminalidade, pois garante condições mínimas socioeconômicas aos dependentes legais do segurado recluso, dificultando que estes sejam aliciados pelo mundo do crime, como frequentemente ocorre, por pressão do crime organizado, que praticamente domina a vida interna e econômica dos presídios.

Embora muito criticado pela opinião pública em geral, o auxílio-reclusão cumpre uma função social importantíssima, sendo em muitos casos a única fonte de renda de famílias de segurados da Previdência Social que se encontram reclusos.

Porém, as críticas a esta prestação previdenciária também surgem de importantes doutrinadores do direito brasileiro como, por exemplo, Sérgio Pinto Martins:

Eis um benefício que deveria ser extinto, pois não é possível que a pessoa fique presa e ainda a sociedade como um todo tenha de pagar um benefício à família do preso, como se este tivesse falecido. De certa forma, o preso é que deveria pagar por se encontrar nesta condição, principalmente por roubo, furto, tráfico, homicídio, etc (MARTINS, 2005, p. 414).

Essas são visões restritivas que não contemplam o todo da função social deste benefício previdenciário. Conforme tratado neste ensaio, entende-se que o benefício de auxílio-reclusão deveria ser extensivo a todos os dependentes de segurados reclusos e não apenas àqueles de baixa renda. A proteção previdenciária, conforme foi abordado, encontra-se no rol dos direitos fundamentais. Sendo assim, o benefício em tela possui grande relevância em um contexto socieconômico de enorme desigualdade e discriminação.

De outra parte, não se pode olvidar que, desde a Convenção de Viena, em 1993, a concepção prevalecente sobre os direitos fundamentais é que são interdependentes, complementares e indivisíveis: os direitos individuais não podem existir apartados dos direitos sociais e econômicos.

Atualmente, parcela considerável da sociedade, prefere marginalizar o problema da violência, em vez de enfrentá-lo, buscando soluções. Algumas vezes, com a sede e o sentimento equivocado de "justiça a qualquer custo", parte da população crítica e é contra ações que objetivam o benefício de todos. 
Esquece-se, frequentemente, que a criminalidade encontra terreno fértil para sua propagação justamente quando o Estado não está presente fomentando políticas sociais. As favelas são exemplos notórios do que a omissão estatal pode gerar.

Verifica-se, atualmente, que a exigência fundamental desta sociedade aterrorizada é um rigor punitivo traduzido em penas severas para os transgressores e a criminalização generalizada de condutas. A cultura do medo que se criou em torno da criminalidade provoca um generalizado desejo de punição, uma intensa busca de repressão e uma obsessão por segurança. A repressão passa a ser a "tábua de salvação" da sociedade e quanto maior for a sua dureza, mais satisfeita ela estará. A segurança torna-se plataforma política e algumas vezes a causa da derrocada de um governo. A promessa é sempre o rigor (PASTANA, 2007, p. 110).

Em um cenário de uma sociedade dominada pelo medo, na qual as pessoas procuram se distanciar do convívio social, cercandose de seguranças e muros, onde uns tem medo dos outros, não fornecer uma proteção digna aos dependentes do trabalhador preso, contribui, e muito, para o aumento da sensação de insegurança.

Acerca da sensação de insegurança, Bauman ensina que a liberdade balizada na segregação social, não é uma forma de liberdade plena:

A promoção da segurança sempre requer o sacrifício da liberdade, enquanto está só pode ser ampliada à custa da segurança. Mas segurança sem liberdade equivale a escravidão (e, além disso, sem uma injeção de liberdade, acaba por ser afinal um tipo muito inseguro de segurança); e a liberdade sem segurança equivale a estar perdido e abandonado (e, no limite, sem uma injeção de segurança, acaba por ser uma liberdade muito pouco livre). Essa circunstância provoca nos filósofos uma dor de cabeça sem cura conhecida. Ela também torna a vida em comum um conflito sem fim, pois a segurança sacrificada em nome da liberdade tende a ser a segurança dos outros; e a liberdade sacrificada em nome da segurança tende a ser a liberdade dos outros. (BAUMAN, 2003, p. 24).

Relevante frisar que o auxílio-reclusão não se trata de um benefício assistencial, uma benevolência social de distribuição de 
renda, mas sim uma prestação previdenciária, amparada por devida fonte contributiva, que respeita o equilíbrio financeiro e atuarial de todo o sistema.

Conclui-se, portanto, que o constituinte brasileiro foi inovador no sentido de considerar a prisão uma contingência social a ser protegida pelo sistema previdenciário, porém esta proteção não deveria ser restrita apenas aos segurados de baixa renda.

Percebe-se, também, uma clara ligação entre a percepção distorcida de parte da população sobre este benefício e a cultura do medo, que por vezes, endossa e fomenta condutas autoritárias.

Para Bauman (2007, p. 60-72) as desigualdades sociais estão em franca progressão, sendo o mercado sem fronteiras (liberalismo econômico) uma receita para a instalação da injustiça e desordem mundial. Estes fatores estão diretamente ligados ao aumento da violência, que gera, por sua vez, um sentimento de medo generalizado, estimulando uma ação defensiva das pessoas.

Esta ação defensiva desemboca em um sentimento de guerra constante. Gera uma polarização de ideias e uma divisão entre ricos e pobres (estes comumente marginalizados), na qual uns tentam se proteger dos outros, sem, bem certo, saberem quem é o verdadeiro inimigo.

\section{REFERÊNCIAS BIBLIOGRÁFICAS}

BAUMAN, Zygmunt. Comunidade: a busca por segurança no mundo atual. Rio de Janeiro: Jorge Zahar, 2003.

BAUMAN, Zygmunt. Confiança e medo na cidade. Tradução Eliana Aguiar. Rio de Janeiro: Zahar, 2005.

BAUMAN, Zygmunt. Tempos Líquidos. Tradução Carlos Alberto Meedeitos. Rio de Janeiro: Zahar, 2007.

BRASIL. Constituição (1988). Constituição da República Federativa do Brasil de $1988 . \quad$ Disponível em: <http://www.planalto.gov.br/ccivil_03/constituicao/constituicao.htm>. Acesso em: 10 abr. 2018.

Lei $\mathbf{n}^{0}$ 8.212, de 24 de julho de 1991. Dispõe sobre a organização da Seguridade Social, institui Plano de Custeio, e dá outras providências. Disponível

em: 
<http://www.planalto.gov.br/ccivil_03/leis/L8212cons.htm>. Acesso em: 10 abr. 2018.

Lei $n^{0}$ 8.213, de 24 de julho de 1991. Dispõe sobre os Planos de Benefícios da Previdência Social e dá outras providências. Disponível em: <http://www.planalto.gov.br/ccivil_03/leis/L8213cons.htm>. Acesso em: 10 abr. 2018.

. Decreto $n^{0}$ 3.048, de 06 de maio de 1999. Aprova o Regulamento da Previdência Social, e dá outras providências. Disponível em: <http://www.planalto.gov.br/ccivil_03/decreto/d3048.htm>. Acesso em: 10 abr. 2018.

CARBONELL, Miguel. Corte Constitucional de Ecuador para el período de transición. El nuevo constitucionalismo en América Latina. $1^{\mathrm{a}}$ ed. Quito: Corte Constitucional del Ecuador, 2010.

GALVÃO, Paulo Braga. Os direitos sociais nas constituições. São Paulo: Ltr, 1981.

GIDDENS, Anthony. Sociologia. $4^{\mathrm{a}}$ ed. Porto Alegre: Artmed, 2005.

GNATA, Noa Piatã Bassfeld. A solidariedade social previdenciária nos 25 anos da Constituição de 1988. SERAU JR., Marco Aurélio; AGOSTINHO, Theodoro Vicente (coords.) A seguridade social nos 25 anos da Constituição. São Paulo: Ltr, Juruá, 2014.

GRAHAM, Stephem. Cidades sitiadas - o novo urbanismo militar. São Paulo: Boitempo, 2016.

HERRERA FLORES, Joaquín. A reinvenção dos direitos humanos. Tradução de Carlos Roberto Diogo Garcia; Antônio Henrique Graciano Suxberger. Jefferson Aparecido Dias. Florianópolis: Fundação Boiteux, 2009.

MARTINS, Sérgio Pinto. Direito da Seguridade Social. Editora Atlas. 22 ${ }^{\mathrm{a}}$ Edição. São Paulo. 2005

PACHECO, Marta Ribeiro. Auxílio-reclusão. Revista de Doutrina da $4^{\mathrm{a}}$ Região, Porto Alegre, n. 30, junho. 2009. Disponível em: <http://www.revistadoutrina.trf4.jus.br/artigos/edicao030/marta_pacheco.ht ml> Acesso em: 14 dez. 2017.

PASTANA, Débora Regina. Cultura do Medo e Democracia: um paradoxo brasileiro. Londrina: Revista Medições. V.10, n. 2, p. 183-198, Jul/Dez, 2005.

PASTANA, Débora Regina. Medo e Opinião Pública no Brasil Contemporâneo. Estudos de Sociologia, Araraquara, v. 12, n. 22, p. 91-116, 2007. 
SANTIN, Janaína Rigo. Estado, constituição e administração pública no século XXI: novos desafios da cidadania e do poder local. Belo Horizonte: Arraes Editores, 2017.

SARLET, Ingo Wolfgang. A eficácia dos direitos fundamentais: uma teoria geral dos direitos fundamentais na perspectiva constitucional. $12^{\mathrm{a}}$ ed. Porto Alegre: Livraria do Advogado, 2015.

SCHWARZ, Rodrigo Garcia. Os direitos e a sindicabilidade judicial das políticas públicas sociais no Estado Democrático de Direito. São Paulo: Ltr, 2013.

SERAU JR., Marco Aurélio. Resolução do Conflito Previdenciário e Direitos Fundamentais. São Paulo: Ltr, 2015.

WACQUANT, Loïc. Punir os pobres: a nova gestão da miséria nos Estados Unidos [A onda punitiva]. 3. ed. rev. e ampl. Trad. de Sergio Lamarão. Rio de Janeiro, REVAN, 2007.

WOLKMER, Antonio Carlos. Constitucionalismo e Direitos Sociais no Brasil. São Paulo: Acadêmica, 1998.

WOLKMER, Antonio Carlos; BATISTA, Anne Carolinne. Direitos Fundamentais e processos de lutas na perspectiva da interculturalidade. PRONER, Carol; CORREAS, Oscar (coord). Teoria crítica dos direitos humanos. Belo Horizonte: Fórum, 2011.

WOLKMER, Antonio Carlos; LORENA, González Pinto (Org.). Justiça e Direito Humanos: para uma discussão contemporânea desde a América Latina. Canoas: Ed. Unilasalle, 2017.

VIANNA, João Ernesto Aragonés. Curso de direito previdenciário. $6^{\mathrm{a}}$ ed. São Paulo: Atlas, 2013. 


\section{EDITORA E GRÁFICA DA FURG CAMPUS CARREIROS \\ CEP 96203900 \\ editora@ furg.br}

JURIS, Rio Grande, v. 28, n. 1, p. 181-201, 2018. 